\title{
O uso das TICs nas salas de recursos TGD
}

\author{
Clarissa Maria Sombrio ${ }^{1}$ \\ Alessandra Pereira Rodrigues ${ }^{2}$
}

\begin{abstract}
Resumo. O uso efetivo das TICs pode ser um forte aliado para acessar, adaptar e construir conhecimentos. O presente artigo faz uma reflexão sobre a utilização das TICs no processo de construção do conhecimento de alunos com Transtorno Global do Desenvolvimento das Escolas Estaduais X e Y. O estudo foi realizado através de observações e entrevistas, de alunos e professores, dentro do âmbito escolar, com o objetivo de verificar como as TICs estão sendo usadas nesses espaços para a construção do conhecimento do aluno. Foi realizada uma análise qualitativa dos dados coletados, segundo alguns fatores estipulados. A análise revelou que os recursos físicos, digitais, humanos e sociais não são explorados de forma adequada, o que não contribuiu para a construção do conhecimento dos alunos envolvidos na pesquisa.
\end{abstract}

Palavras-chave: inclusão digital - transtorno global de desenvolvimento atendimento educacional especializado

\section{The contribution of ICT use in building the knowledge of people with pervasive developmental disorders}

\begin{abstract}
The effective use of ICTs can be a powerful ally to access, adapt and build knowledge. This article reflects on the use of ICTs in the process of knowledge construction of students with Pervasive Developmental Disorder State Public Schools X and Y. The study was conducted through observations and interviews of students and teachers within the school context in order to determine how ICTs are being used in these spaces for the construction of student knowledge. We performed a qualitative analysis of data collected, according to some fudge factors. The analysis revealed that the physical resources, digital, human and social are not operated properly, which did not contribute to the construction of knowledge of the students involved in research
\end{abstract}

Keywords: digital inclusion - global development disorder - specialized educational services

\section{Introdução}

A Educação Especial no Brasil sofreu várias mudanças desde a Conferência Mundial sobre Necessidades Educativas Especiais na Espanha em 1994. Desde então, o governo brasileiro procura implantar uma política educacional na qual pretende democratizar o

\footnotetext{
${ }^{1}$ Aluna do Curso de Especialização em Mídias na Educação da UFRGS. E-mail: cacasombrio@gmail.com

${ }^{2}$ Professora do Instituto Federal de Educação, Ciência e Tecnologia Sul-rio-grandense, doutoranda no Programa de Pós-graduação em Informática na Educação da UFRGS. E-mail: ale@ufrgs.br
} 
ensino, através da garantia do ensino fundamental gratuito e obrigatório para todos, sem exceção. A legislação brasileira de Educação Especial tem como objetivo organizar e transferir o atendimento dos alunos das escolas especiais para as escolas regulares.

O processo de inclusão digital acarreta mudanças do cenário da inclusão escolar, pois com a chegada das Novas Tecnologias de Informação e Comunicação (NTICs) sendo utilizadas como recursos nas escolas é possível inovar as práticas pedagógicas, sendo para isso necessário que os professores estejam capacitados a explorar o potencial pedagógico das mesmas.

As salas de recursos de Transtorno Global de Desenvolvimento (TGD), através de seu Atendimento Educacional Especializado (AEE) oferecido às pessoas com necessidades educativas especiais (PNEEs) foram criadas com objetivo de auxiliar no processo de inclusão escolar, dando suporte e apoio à educação regular, proporcionando às PNEEs um trabalho complementar específico, para que possa superar e/ou compensar suas limitações.

O presente artigo tem como objetivo relatar a pesquisa realizada sobre o trabalho pedagógico desenvolvido na sala de recursos TGD, através do uso das TICs, no auxílio da PNEE no processo de construção do conhecimento. Os resultados são apresentados, através da análise qualitativa dos dados coletados, nas observações e entrevistas, realizadas com professores e alunos, que estão vinculados à sala de recursos TGD das Escolas Estaduais Y e X, ambas localizadas em Porto Alegre.

\section{Inclusão Escolar}

A Educação Especial vem passando por mudanças, com o objetivo de organizá-la e de transferir o atendimento dos alunos das escolas especiais para as escolas regulares. A proposta dessa reforma é de proporcionar uma educação de qualidade para todos e mudar o que for necessário para isso.

A declaração final da Conferência Mundial sobre Necessidades Educativas Especiais determinou que os sistemas de ensino devem ser planejados em cima das diversidades encontradas dentro da realidade de cada escola, pois cada criança, tem suas características, interesses e necessidades, incluindo as com necessidades especiais, que devem ter acesso as escolas regulares e deverão ser o centro desses planejamentos (DECLARAÇÃO..., 1994).

Conforme o art. 8, inciso II da Constituição da República Federativa do Brasil de 1988 determina que os alunos inclusos devam ser distribuídos pelas várias classes do ano escolar, de forma que suas diferenças beneficiem o grupo, dentro do princípio de educar para a diversidade.

A escola inclusiva, segundo o Parecer no 441/2002 do CEED/RS, adapta-se às necessidades de seus alunos e não espera que eles se adaptem a um modelo previamente fixado. Sendo assim, o papel do professor nessa escola é o de facilitador no processo de busca do conhecimento do aluno. É ele quem organiza situações de aprendizagem adequadas às diferentes necessidades, oferecendo oportunidade de desenvolvimento aos alunos.

Com o objetivo de auxiliar no processo de inclusão escolar e dar apoio à educação regular no atendimento da PNEE foram criados os serviços de apoio pedagógico especializado de acordo com o Parecer n $n^{\circ}$ 56/2006 do CEED/RS. 
A Resolução $\mathrm{n}^{\circ} 4$ do CNE institui as diretrizes operacionais para o AEE na educação básica, modalidade da Educação Especial, onde o professor especialista desenvolve um trabalho de complementação ou suplementação à formação do aluno através de recursos e estratégias que facilitem a sua aprendizagem. (BRASIL, 2009, p. 1). Para esse tipo de atendimento o público-alvo são alunos com deficiência, Transtorno Global do Desenvolvimento e altas habilidades, sendo realizadas nas salas de recursos multifuncionais.

Todas essas mudanças têm um único objetivo o de educar para diversidade levando a escola a mudanças rápidas e profundas, onde seus alunos deverão conviver sem nenhum tipo de discriminação, sendo estimulados, através do convívio social, a desenvolver suas habilidades e competências da melhor maneira possível.

\subsection{Atendimento Educacional Especializado}

O AEE é realizado nas salas de recursos e tem como objetivos desenvolver ações inclusivas e uma proposta pedagógica que auxilie o processo de construção do conhecimento e inclusão do aluno na sociedade. (RIO GRANDE DO SUL, 2009, p. 12).

O trabalho desenvolvido, pelo professor especializado, na sala de recursos, deve ser planejado de acordo com o plano de estudos da série do aluno, levando em consideração as necessidades do mesmo, buscando sempre a construção da sua autonomia (RIO GRANDE DO SUL, 2009).

O aluno com necessidades educativas especiais precisa de sociabilização, como parte importante de sua escolarização, para que desenvolva suas potencialidades, dentro das suas limitações. As atividades escolares do aluno especial devem seguir o mesmo programa de conteúdos trabalhado com os demais alunos, mesmo que o nível de apreensão não seja o mesmo. As aprendizagens decorrentes dessas atividades devem ser complementadas, no turno inverso, no AEE, com orientação de professor especializado, devendo também realizar atividades próprias da sua idade. Assim, o aluno com deficiência, Transtornos Globais do Desenvolvimento e altas habilidades ou superdotação incluído na classe comum acompanhará seus colegas, tendo valorizadas suas superações e seus progressos (RIO GRANDE DO SUL, 2010).

\subsection{Transtorno Global do Desenvolvimento}

Segundo o Ministério da Saúde (2008):

Transtorno Global de Desenvolvimento é um grupo de transtornos caracterizados por alterações qualitativas das interações sociais recíprocas e modalidades de comunicação e por um repertório de interesses e atividades restrito, estereotipado e repetitivo. Estas anomalias qualitativas constituem uma característica global do funcionamento do sujeito, em todas as ocasiões (MINISTERIO DA SAÚDE, 2008).

Os transtornos apresentam-se em várias formas como (MINISTÉRIO DA SAÚDE, 2008): Autismo Infantil, Autismo Atípico, Síndrome de Rett, Transtorno Desintegrativo da Infância, Transtorno com hipercinesia associada a retardo mental e a 
movimentos estereotipados, Síndrome de Asperger e Transtornos Globais do Desenvolvimento sem outra especificação.

Durante o período de escolarização os alunos com TGD requerem do sistema educacional diversidade e personalização, segundo Rivière (2004), o que de acordo com a Legislação Brasileira de Educação Especial deve ser oferecido no Brasil através do AEE. Ainda assim devem ser levados em consideração os seguintes critérios listados pelo mesmo autor:

a) nível de comunicação e linguagem para sua integração;

b) alterações de conduta;

c) grau de flexibilidade cognitiva e comportamental;

d) nível de desenvolvimento social;

e) para alunos TGD recomendam-se escolas pequenas, com número mínimo de alunos, evitando assim escolas barulhentas e "despersonalizadas", que sejam estruturadas;

f) uma escola que trabalhe em conjunto, professores da sala regular, professores especialistas, equipe diretiva, no atendimento dos alunos com TGD;

g) a escola deve possuir recursos pedagógicos;

h) a escola deve proporcionar aos colegas dos alunos TGD orientação para compreenderem e apoiarem suas aprendizagens e relações.

É importante seguir todos esses critérios, pois o aluno TGD apresenta dificuldade de interação social, o que muitas vezes os levam a situações de desorganização junto a seus pares.

\subsection{Inclusão Digital na Educação}

Segundo Montardo e Passerino (2007) a inclusão é um processo que busca a qualidade de vida, desenvolvimento humano, autonomia de renda e equidade de oportunidades dos indivíduos.

O processo de inclusão leva às escolas, segundo Mittler (2003), a uma mudança no currículo escolar, no processo de avaliação e na metodologia, onde se prioriza a diversidade e oferece tudo que for necessário para responder as necessidades dos PNEEs. Dentro desse contexto de inclusão escolar, as tecnologias disponibilizam aos educadores uma gama de recursos. $\mathrm{O}$ mundo digital permite mudanças, porém as tecnologias permanecem inexploradas pela inércia da cultura tradicional, pelo medo, pelos valores consolidados. Por isso, sempre haverá um distanciamento entre as possibilidades e a realidade.

Segundo Moran (2008) as tecnologias não chegam à todos por igual, por isso são importantes as políticas de inclusão como capacitar professores para a prática inclusiva, educando com cidadania e dignidade, princípios presentes na Constituição. (MORAN, 2008, p. 51-52).

Moran (2008) afirma também que escolas não conectadas são escolas incompletas, onde alunos sem acesso contínuo às redes digitais estão excluídas do acesso à informação variada e disponível on-line.

Neste contexto, Warschauer (2006, p.21) afirma que, o acesso às TICs vai além de fornecer computadores e internet, é necessário para que haja inclusão digital que recursos físicos, digitais, humanos e sociais participem desse processo. $\mathrm{O}$ autor descreve 
os elementos para cada um dos fatores (físicos, digitais, humanos e sociais) necessários para garantir a inclusão digital. Os recursos físicos incluem o acesso a computadores e a conexão de internet, os digitais seriam o material digital disponível na internet, os recursos humanos referem-se ao letramento e educação, que são importantes já que as habilidades de leitura e pensamento continuam sendo decisivas para a capacidade de utilização da internet e a educação também ajuda a determinar como as pessoas usam a internet e os benefícios que elas obtêm disso e os recursos sociais são as estruturas comunitárias, institucionais e da sociedade que apoiam $\mathrm{o}$ acesso à TIC (WARSCHAUER, 2006).

Cada recurso contribui para que as TICs possam ser usadas e exploradas de maneira efetiva para acessar, adaptar e criar o conhecimento, sendo que o resultado da boa utilização ajudará a ampliar e desenvolver esses recursos, bem como fomentar um círculo virtuoso que promova o desenvolvimento e a inclusão social, como mostra a figura 1. Caso estes recursos não sejam bem utilizados podem levar a exclusão.

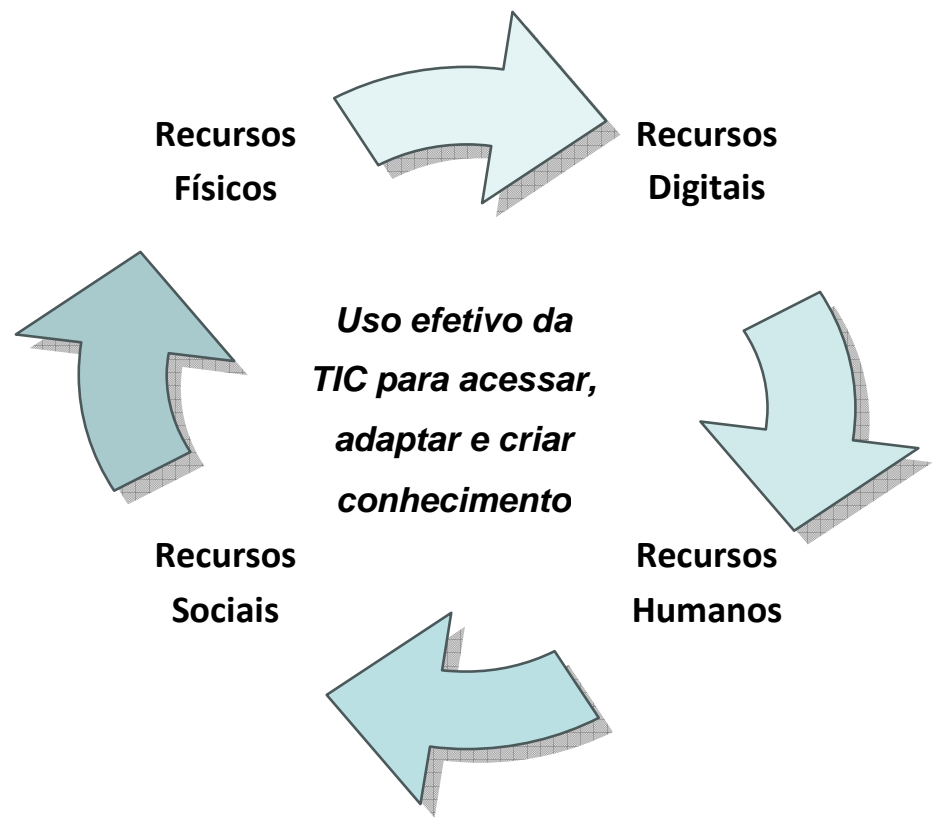

Figura 1- Recursos que contribuem para o acesso à TIC (Adaptado de Warschauer, 2006, p. 76).

Portanto, o acesso às TICs favorece a inclusão social, através da melhora na educação, assistência médica e administração pública, bem como a superação da exclusão social, no mundo digital (WARSCHAUER, 2006). Mas para que esse processo aconteça no âmbito escolar é necessário que os professores sejam capacitados a explorar os recursos físicos e digitais, tornando-se assim mediadores na construção do conhecimento do aluno no mundo digital. Para isso, é necessário que a instituição mantenedora da escola disponibilize essa formação e espaços para acesso aos computadores.

\section{Material e Métodos}

O quadro atual da educação no Brasil apresenta uma maior diversidade de alunos nas escolas, porém continuam oferecendo o mesmo ensino, apesar das necessidades serem outras (GUIJARRO, 2005), por isso a PNEE, tem garantida por lei o acesso à sala de 
recursos, mediante identificação de suas necessidades educacionais especiais, de acordo com o art. $6^{\circ}$ da Resolução CNE/CEB n ${ }^{\circ} 2 / 2001$, como meio de auxílio nesse processo de inclusão escolar (BRASIL, CNE, 2001).

Pensando nessa situação o estudo relatado aqui neste artigo buscou responder a seguinte indagação: De que forma o trabalho pedagógico desenvolvido na sala de recursos TGD, através do uso das TICs está auxiliando a PNEE no processo de construção do conhecimento?

Nesta pesquisa qualitativa foi utilizado como procedimento técnico o estudo de caso, que segundo Yin (2010) investiga um fenômeno moderno dentro de seu contexto real, onde foram utilizadas as técnicas de revisão bibliográfica, observação direta e entrevistas para coleta e posterior análise de dados. As entrevistas foram realizadas a partir de instrumentos previamente elaborados, mas buscando a informalidade com o objetivo de deixar os entrevistados mais confortáveis e com isso obter mais informações. As observações foram realizadas durante os atendimentos dos alunos nas salas de recursos TGD, onde a pesquisadora se posicionou de forma que sua presença não interferisse no atendimento.

Os sujeitos envolvidos na pesquisa foram três alunos que necessitam de AEE e frequentam a sala de aula regular e a sala de recursos TGD, de duas escolas públicas de Porto Alegre. Essas salas são distribuídas em escolas pólos, de acordo com a demanda de cada região da cidade. Além destes, três professores que atendem esses alunos na sala de aula regular e dois professores especialistas que atuam nas salas de recursos TGD nessas escolas.

\section{Resultado e Discussão}

A partir dos dados coletados foi realizada uma análise qualitativa dos dados obtidos nas entrevistas realizadas com os professores das salas de aulas regulares e de recursos. Ao indagar sobre a abordagem pedagógica utilizada, o professor L da Escola X relata que:

"Trabalho com o Programa Alfa e Beto, e nós temos todo o acompanhamento nos livros e o aluno tem que acompanhar e não consegue então eu acabo dando trabalhos diferentes pra ele, folhinhas pra ele pintar. Agora eu fiquei muito feliz, pois eu faço as letrinhas e ele consegue passar por cima, porque antes ele não conseguia".

A Escola X adota o Programa Alfa e Beto oferecido pela Secretaria de Educação do Rio Grande do Sul, onde todo o trabalho de alfabetização é realizado em livros. Neste caso, não foi evidenciado durante as observações algum tipo de adaptação que permitisse a inclusão do aluno.

Porém, o professor $\mathrm{M}$, da Escola $\mathrm{Y}$, tem o conhecimento de que é necessário elaborar atividades diferenciadas para o aluno, mas não o faz deixando essa função para a sala de recursos, considerando que o AEE da sala de recursos auxilia para que o aluno acompanhe as atividades de sala de aula, fazendo com que ele se sinta incluído. A sala de recursos traz autonomia para esse aluno ao trabalhar suas dificuldades, um dos fatores que favorece a inclusão, o que fica evidenciado quando o professor especialista da sala de recursos, da Escola Y, afirma que as atividades são planejadas " [...] de acordo com as necessidades de aprendizagem do aluno e faço uma adequação junto ao 
currículo escolar do aluno". O mesmo trabalho é feito pelo professor especialista $\mathrm{N}$, da Escola X, o qual faz seu planejamento individual respeitando as particularidades e as necessidades de cada PNE.

$\mathrm{O}$ professor $\mathrm{C}$, da escola $\mathrm{X}$, que adota a mesma abordagem pedagógica do professor L, da mesma escola, faz adaptações das atividades, atendendo as dificuldades desse aluno, fazendo com que ele sinta-se incluído dentro do contexto da sua turma. Durante a entrevista o professor C relatou: "Eu flexibilizo, eu cobro as coisas dele, mas com flexibilidade [...]".

Quando falamos em inclusão social também precisamos da inclusão afetiva acolhendo, motivando, valorizando, dando força e entusiasmo aos alunos, pois só assim terão mais autonomia no seu dia-a-dia escolar, o que comprovamos na seguinte fala do professor L, da Escola X: "Ele adora ir para sala de recursos. Eu noto dele ir na sala dá vontade de querer fazer as atividades em sala de aula". O professor que trabalha na sala de recursos TGD no seu AEE motiva seus alunos, pois faz um trabalho planejado com suas necessidades, de forma que ele consiga superá-las, no decorrer dos encontros. Moran (2008) diz que: “[...] a afetividade é um componente fundamental pedagógico e contribui decisivamente para o sucesso pessoal e grupal." O professor L nos comprova essa motivação na seguinte fala:

"Quando ele volta pra sala de aula ele volta também mais tranquilo, porque antes até para ficar no lugar dele era difícil, não vou dizer que ele não sai, caminha, mas antes ele não ficava mesmo, até para sentar, ele sentava em baixo da mesa, ele não sentava na cadeira."

Já as atividades realizadas em sala de aula pelo mesmo professor não são significativas para esse aluno, pois nunca consegue concluí-las. Elas são dadas aleatoriamente sem uma adequação as suas necessidades dentro do Programa Alfa e Beto e também não se percebe um planejamento prévio. O próprio professor afirma que o aluno K não é estimulado a dirigir a sua aprendizagem, portanto não há também uma inclusão afetiva.

Nas perguntas relacionadas ao uso das TICs para a construção do conhecimento do aluno PNEE, todos os professores concordaram que o computador auxilia nesse processo, de acordo com as seguintes afirmações:

"É básico pelo interesse dele, eu fiz muita conquista pelo computador, em conquistar o interesse deles ficaram aqui, porque pra eles é um sonho. Na concepção deles essa sala aqui é um prêmio que eles têm, eles ganham de prêmio a vinda aqui."

"Contribui e facilita bastante, pois muitos alunos tem dificuldade na escrita, também se mostram muito melhores usando o computador, demostram mais interesse. Então uma atividade que parece ser muito chata escrevendo no computador se torna ótima de grande interesse."

Porém, nem todos fazem o uso do computador, em sala de aula, de maneira adequada conforme a seguinte fala do professor L, da Escola Y: "O computador é o que 
tem na sala dos professores. Então eu levo esse computador e coloco vídeos do alfabeto que gravei da internet". O professor C, da mesma escola, também faz uma subutilização do computador, pois o utiliza apenas para demonstrar um vídeo. Poderia ser usado para jogos pedagógicos, pesquisas, redes sociais, blogs, entre outras atividades que despertariam a motivação do aluno.

A seguir uma análise de acordo os fatores, segundo Warschauer (2006), necessários para a inclusão digital com o objetivo de promover a inclusão social.

O professor $\mathrm{M}$, apesar de ter na Escola $\mathrm{Y}$, um completo laboratório de informática, com 32 computadores com banda larga e wireless, não o usa, pois acha difícil gerenciar a sua turma, pois tem 34 alunos em sala de aula, portanto não há aproveitamento dos recursos físicos, computadores e conectividade, disponibilizados na escola.

A escola localizada na Ilha da Pintada possui na sua sala de recursos, três computadores, um notebook, uma impressora jato de tinta e um scanner, mas não possui acesso à internet, devido a sua localização. No entanto, o professor da sala de recursos leva seu modem $3 \mathrm{G}$, mas nem sempre conecta devido à falta de sinal. $\mathrm{O}$ local não possui laboratório de informática, contando com um computador na sala dos professores. Porém percebe-se que não há um aproveitamento adequado dos recursos físicos, disponibilizados na escola, como já relatado e a inacessibilidade aos recursos digitais.

O professor especialista $\mathrm{H}$, na sala de recursos da Escola $\mathrm{Y}$, a qual possui um computador com banda larga e uma impressora jato de tinta, faz um bom aproveitamento dos recursos físicos e digitais, pois afirma:

"Utilizamos a internet para buscar gifs, ler sites de notícias, criamos jogos de dominós, jogos on-line (memória, tabuada, palavras, raciocínio). Os alunos retiram gravuras ou notícias da internet e colam no Word ou Power Point e salvam seus arquivos em pastas no desktop."

Quanto aos recursos humanos, letramento e educação, foi observado o despreparo, de quatro professores (três da sala de aula regular e um professor especialista da Escola $\mathrm{X}$ ) dos cinco que participaram da pesquisa, pois não tiveram uma formação pedagógica para o uso das TICs, na sala de aula, como uma ferramenta de apoio à construção do conhecimento. Durante as observações do AEE dos alunos na sala de recursos, ficou claro o despreparo do professor especialista N, da Escola X, pois independente das dificuldades de cada PNEE, limita-se as mesmas atividades, jogo de pintura da Turma da Mônica e o uso do Word para a grafia de palavras e frases.

Os recursos sociais, estruturas comunitárias, institucionais e da sociedade, nesse estudo está representado pela escola, que oferece aos alunos PNEE, um espaço de inclusão digital, principalmente aos alunos da Escola X, onde para eles o computador é uma novidade, pois muitos nem luz possuem em suas casas, devido à precariedade do local, por não possuírem condições financeiras e porque muitas famílias vivem ali da coleta de material reciclável.

Com essa análise pode-se concluir que os recursos não estão sendo utilizados de forma efetiva, o que seria necessário para que desenvolvessem a inclusão digital com 
vistas à inclusão social e assim auxiliassem no processo de construção do conhecimento do aluno.

\section{Conclusões}

O estudo relatado neste artigo teve como objetivo constatar qual a contribuição das TICs na construção do conhecimento dos alunos com Transtorno Global do Desenvolvimento, que frequentam as salas de recursos das escolas X e Y. Para atingir esse objetivo foi utilizado o método de estudo de caso, apoiado pelos instrumentos de observações e entrevistas.

Através da análise dos fatores necessários para a inclusão digital com vistas a inclusão social propostos por Warschauer (2006), considerando o estudo de caso realizado conclui-se que em relação aos recursos físicos, apesar das escolas estarem bem equipadas, a falta de conectividade limita o trabalho do professor, pois dificulta a exploração dos recursos digitais.

Constatou-se também que, os recursos digitais disponíveis poderiam ser melhor explorados, pois nos atendimentos os alunos fazem sempre as mesmas atividades, utilizando os mesmos materiais. É necessário que esse momento de aprendizado seja significativo para os alunos, através de escolhas adequadas desses recursos.

Houve uma motivação muito grande por parte dos alunos para usarem o computador, durante as aulas, mas nem sempre o mesmo foi usado de maneira adequada as suas necessidades. Isso ocorreu pela falta de preparo dos recursos humanos no uso das TICs no AEE, pois é necessário que o professor especialista tenha formação para fazer uso apropriado das tecnologias, onde possa através do planejamento, de acordo com as necessidades de cada aluno, fazer as mediações necessárias para que esse aluno, investigue, questione, pense, para assim construir seu conhecimento.

Constatou-se também uma diferença entre a sala de aula regular e o AEE realizado nas salas de recursos, quanto à motivação dos alunos na realização das atividades propostas, pois na sala de recursos, as atividades são planejadas de acordo com as dificuldades de cada um, o que contribui para a sua inclusão escolar, pois auxilia no desenvolvimento da sua autonomia. $\mathrm{Na}$ sala de aula regular esse atendimento individualizado se torna mais complicado em função do número de alunos, o que não deveria acontecer, pois segundo o Parecer 56 da Comissão Especial de Educação Especial (2006) o número de alunos de inclusão, com necessidades educacionais semelhantes, nas salas de aulas do ensino fundamental séries iniciais é de no máximo três, não devendo a turma exceder a vinte alunos.

Quantos aos recursos sociais o ambiente da sala de recursos, contribui para uma melhor socialização desses alunos, principalmente quando desenvolvem atividades em duplas ou grupos.

Como resultado do estudo realizado constatou-se que as dificuldades encontradas para a melhor exploração desses recursos não contribuíram para que os alunos, através do uso das tecnologias, desenvolvessem a capacidade de acessar, adaptar e construir seu conhecimento. As TICs foram subutilizadas e portanto não houve um aproveitamento pedagógico adequado.

O estudo realizado mostrou ainda que as salas de recursos TGD aliada aos recursos das TICs, se bem utilizados, podem contribuir no desenvolvimento cognitivo da PNEE, pois auxiliam o aluno na superação e compensação das suas limitações, desenvolvendo suas potencialidades. 


\section{Referências}

BRASIL. Conselho Nacional de Educação. Câmara de Educação Básica. Resolução CNE/CBE n'2/2001. Disponível em: <http://portal.mec.gov.br/cne/arquivos/pdf/ CEB0201.pdf>. Acesso em: 17 jul. 2010.

BRASIL. Ministério da Educação. Resolução nº . 4, de 2 de outubro de 2009. Institui as diretrizes operacionais para o atendimento educacional especializado na educação básica, na modalidade educação especial. Disponível em: < http://portal.mec.gov.br/ dmdocuments/rceb004_09.pdf.>. Acesso em: 14 out. 2010.

DECLARAÇÃO de Salamanca: sobre princípios, política e práticas na área das necessidades educativas especiais. 1994. Disponível em: <http://portal.mec.gov.br/ seesp/arquivos/pdf/salamanca.pdf>. Acesso em: 20 ago. 2010.

GUIJARRO, M. R. B. Inclusão: um desafio para os sistemas educacionais. Ensaios Pedagógicos: construindo escolas inclusivas, Brasília, 2005.

MINISTÉRIO DA SAÚDE. Classificação Estatística Internacional de Doenças e Problemas Relacionados à Saúde. Disponível em:< http://cid10.datasus.gov.br/>. Acesso em: 19 ago. 2010.

MITTLER, P. Educação inclusiva: contextos sociais. Porto Alegre: Artmed, 2003.

MORAN, J. M. As muitas inclusões necessárias na educação. In: RAIÇA, Darcy (Org.). Tecnologias para a educação inclusiva. São Paulo: AVERCAMP, 2008. p. 38-52.

PASSERINO, L. M.; MONTARDO, S. P.Inclusão social via acessibilidade digital: proposta de inclusão digital para pessoas com necessidades especiais. Revista Compós, Belo Horizonte, 2007. Disponível em: <http://www.compos.org.br/seer/index.php/ ecompos/article/view/144/145>. Acesso em: 02 ago. 2010.

R RIO GRANDE DO SUL. Comissão Especial de Educação Especial. Parecer n. 56/2006. Orienta a implementação das normas que regulamentam a educação especial no sistema estadual de ensino do Rio Grande do Sul. Disponível em: <http://www.ceed. rs.gov.br/portal/index.php?categoria=1\&palavra=parecer+56> Acesso em: 11 out. 2010.

RIO GRANDE DO SUL. Comissão Especial de Educação Especial. Parecer n. 441/2002. Parâmetros para a oferta da educação especial no sistema estadual de ensino. Disponível em: <http://www.ceed.rs.gov.br/portal/index.php>. Acesso em: 10 out. 2010.

RIO GRANDE DO SUL. Secretaria da Educação. Seção Educacional Especial. Atendimento educacional especializado sala de recursos TGD transtornos globais do desenvolvimento. Porto Alegre: p. 1- 6, 2009.

RIO GRANDE DO SUL. Conselho Estadual de Educação. Parecer no 251/2010. Disponível em: <http://www.ceed.rs.gov.br/arquivos/1271447338pare_0251.pdf>. Acesso em: 10 out. 2010.

RIVIÈRE, Á. O autismo e os transtornos globais do desenvolvimento. In: COLL, C.; MARCHESI, A.; PALACIOS, J. (Org). Desenvolvimento psicológico e educação: transtornos de desenvolvimento e necessidades educativas especiais. Porto Alegre: Artmed, 2004. cap. 12, p. 239-254.

WARSCHAUER, M. Tecnologia e inclusão social: a exclusão digital em debate. São Paulo: Editora SENAC, 2006. cap.1-2, p. 29-78. 
YIN, R. K. Estudo de caso: planejamento e métodos. São Paulo: Bookman, 2010. 